\title{
La montaña vacía: del despertar al sueño ${ }^{1}$
}

\section{The empty mountain: from awakening to dream}

\author{
Sergio LARRIERA
}

\section{Resumen}

En este artículo se comenta el proyecto del escultor Eduardo Chillida de vaciar una montaña. La elección había recaído en Tindaya, en la isla de Fuerteventura (Canarias). La noción de "vacío", esencial para la escultura desde comienzos del siglo xx, es puesta en conexión con la idea psicoanalítica de "extimidad", concepto capital en el proceso de constitución del sujeto. Chillida, al introducir el vacío en la montaña y al conectar ese interior con la luz y el mar, habría llevado al espectador a vivenciar la extimidad como íntimo exterior, realizando así un aprendizaje sobre el modo de habitar la tierra. El proyecto surgió como un despertar de Chillida, volviendo por la imposibilidad de realizarlo al estado de sueño.

Palabras clave: sujeto, psicoanálisis, creatividad, extimidad

\begin{abstract}
This article discusses the project of sculptor Eduardo Chillida to empty a mountain. The choice had fallen on Tindaya, on the island of Fuerteventura (Canary Islands). The notion of "empty", essential for sculpture from the early twentieth century, is put in connection with the psychoanalytic idea of "extimity" concept capital in the process of constitution of the subject. Chillida,
\end{abstract}

\footnotetext{
${ }^{1}$ Alemán, J. y Larriera, S., Desde Lacan: Heidegger. Textos reunidos, Málaga, Miguel Gómez ediciones, 2009. Para la producción de este artículo he utilizado algunos fragmentos del capítulo «Arte y pensamiento» de dicho libro.
} 
entering the vacuum in the mountain and connecting the interior with the light and the sea, would have led the viewer to experience the intimate exterior as foreign, thus making learning how to live on earth. The project emerged as an awakening of Chillida, returning because the impossibility to realize it to the dream state.

Key words: subject, psychoanalysis, creativity, extimity

Yo aspiro a definir lo tridimensional (hueco) por medio de lo tridimensional (pleno), estableciendo al mismo tiempo una especie de correlación y diálogo entre ellos. Gracias a estas correlaciones, los volúmenes exteriores a los que tengamos acceso serán nuestra guía segura para llegar a conocer, al menos en su espíritu, espacios ocultos.

Eduardo Chillida ${ }^{2}$

\section{EI vacío en la escultura}

A mediados del siglo XX, la escultura había consolidado su revolución, experimentando el espacio de una manera radicalmente nueva, a resultas de la cual surgió una inédita valoración del vacío. Antes del cubismo analítico y del constructivismo ruso, "jamás se había definido lo escultórico por el hueco, nunca se había preferido como espacio escultural el espacio libre"’.

Este proceso prosiguió reduciendo la masa escultórica a planos y líneas (placas de bronce, alambre, chapa), mientras que otra vía seguida por la escultura de grandes dimensiones fue la de ofrecer una síntesis de masa y vacío. Otros se inclinaron por la masa, afirmando así su propiedad en tanto elemento definidor.

En la década de los 50 surgen las primeras obras de Eduardo Chillida. En un texto en el que analiza el recorrido artístico del escultor vasco a propósito de la obra instalada en Gijón, Elogio del horizonte, Fernando Huici señala los diver-

${ }^{2}$ Chillida, E., Escritos. Madrid, La Fábrica, 2005, p. 53.

${ }^{3}$ Marín Medina, J., José Luis Fernández. Cuerpo y forma de su escultura, Madrid, Edarcón, 1980, p. 12 . 
sos modos que aquel tiene de tratar el vacío. La serie de esculturas en madera de los Abesti Gogorra constituye un punto de inflexión en este respecto: "Fruto de una inversión en el problema del espacio, tal y como su escultura había venido abordándolo hasta entonces, y en la necesidad consecuente de trabajar con volúmenes positivos mayores que definieran espacios interiores de dimensiones progresivamente menores..."4.

Los Abesti Gogorra culminan en el quinto ejemplar, esta vez en granito, (jardines del Museo de Bellas Artes, Houston, 1966). Si a lo largo de la serie "el crecimiento progresivo de las dimensiones se corresponde, punto por punto, con una más fluida articulación de ese espacio interior, se puede decir que la obra de Chillida, asimismo, va pasando de unas estructuras que, en la década de los cincuenta, tienden a desplegarse en el espacio físico, a otras estructuras que se repliegan para envolver el espacio interior en los sesenta"'. En esa segunda etapa del camino aflorará un ciclo denominado Alrededor del vacío. Este proceso continúa en esa dirección, siendo hitos de ese camino, a nuestro juicio, tres grandes obras, dos de ellas ya realizadas: Peine del viento en San Sebastián, y Elogio del horizonte, en Gijón. Nosotros nos ocuparemos especialmente de la tercera, o mejor dicho, de su proyecto: La montaña vacía. Pensamos que en los principios en que se sustenta esta proyectada obra culmina el procedimiento de extimización, llevando Chillida al espectador al interior de la tierra, para que sea el soporte de un anudamiento de lugares fundantes de un nuevo espacio.

¿En qué consiste esta idea de vaciar una montaña? ¿Cuáles son sus antecedentes?

Lawrence Boulting realizó en 1985 una película sobre Eduardo Chillida, en la cual se ve al escultor vasco empequeñecido por las descomunales proporciones de remotos templos. Alabastro y luz. El artista mira a uno y otro lado, a lo alto, tratando de ver: "Creo que mirar es una cosa y ver es otra. Mirar es intentar ver. Normalmente ver es muy difícil. Sé que en el interior de las cosas que estoy mirando hay una gran cantidad de cosas que soy incapaz de ver pero que existen".

A mediados de 1995 se hizo público que en las Islas Canarias, exactamente en la isla de Fuerteventura, Eduardo Chillida llevaría a cabo su proyecto de vaciar una montaña. La elegida había sido Tindaya, una montaña mágica y

\footnotetext{
${ }^{4}$ Huici, F., Elogio del Horizonte. Eduardo Chillida, Oviedo, Progreso Editorial, 1990, p.36

${ }^{5}$ Ibidem, p.37.

${ }^{6}$ Boulting, L., Chillida, Waveband Film Productions y WDR Köln, Coproducción de RMArts Euskal Telebista, 1985.
} 
sagrada, en cuya cima hay petroglifos podomorfos a los que se relaciona con el culto astral. En esa nota periodística declaraba: "Hace unos años hice una escultura en alabastro, titulada Montaña vacía. Me desperté una noche y empecé a imaginar la posibilidad de trabajar directamente en una montaña".? En estas palabras del artista hay que destacar que no se trataba de un sueño, sino de un despertar. Chillida despierta, es arrancado del sueño para empezar a concebir la obra: llevar al hombre al interior de la tierra para que, al mirar las cosas -el sol, la luna, el mar- al ser mirado por ellas, pueda verlas.

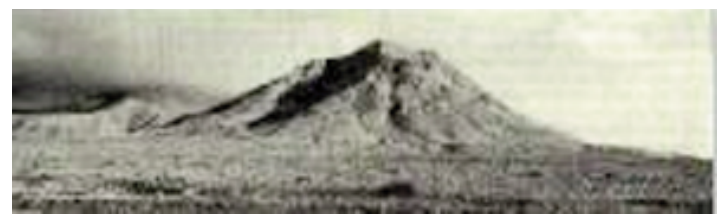

Samaniego, F. «Chillida penetra en una montaña sagrada», El País, 30 de julio de 1995.

\section{El vacío no es la nada}

"El vacío no es la nada. Tampoco es carencia alguna. En la encarnación escultórica el vacío interviene al modo de una fundación de lugares, una fundación que esquematiza y busca". Estas palabras pertenecen al ensayo que Heidegger dedicó a Eduardo Chillida en 1969. El pensador eligió a este artista para que realizase siete lithocollages que acompañasen al texto.

En este ensayo titulado El arte y el espacio, Heidegger se interroga sobre el espacio en relación a la escultura. Para ello debe diferenciar el espacio técnicofísico del espacio artístico y del espacio del actuar y el circular cotidianos. Pero: ¿no son estos últimos simples variaciones condicionadas subjetivamente del único y verdadero espacio, el espacio cósmico objetivo?

Hasta que no experimentemos lo propio del espacio, el discurso acerca del espacio artístico permanecerá oscuro. Pues de entrada queda indeterminado de qué modo el espacio gobierna en la obra de arte.

"El espacio, en el que la forma escultórica puede hallarse previamente como objeto ya presente; el espacio, al que encierran los volúmenes de la figura; el espacio que es como vacío entre volúmenes. Estos tres espacios, ¿no siguen siendo acaso, en la conjunción de su juego mutuo, tan sólo

\footnotetext{
${ }^{7}$ Samaniego, F., Chillida penetra en una montaña sagrada, El País, 30 de julio de 1995. ${ }^{8}$ Heidegger, M., «El arte y el espacio», en el libro Barañano, K., Chillida, Heidegger, Husserl. El concepto de espacio en la filosofía y la plástica contemporánea, Universidad del País Vasco, 1992, p.59.
} 
descendientes de aquel espacio técnico-físico? ¿No es así a pesar de que la configuración artística no permite la injerencia de cálculos numéricos?

Para encontrar lo más propio del espacio Heidegger se dirige a oír lo que habla en el lenguaje. A través de un largo recorrido por la lengua llega a la conclusión de que para pensar el juego mutuo de la escultura con el espacio hay que partir de la experiencia del paraje y del lugar. La escultura no es la conquista del espacio sino la encarnación de lugares. "Una encarnación que, cuando abre un paraje y lo custodia, mantiene lo libre reunido a su alrededor, presta permanencia a cada una de las cosas, y otorga al hombre un habitar en medio de ellas".

Al dar tal función esencial al lugar en la escultura, y al separar radicalmente la encarnación de lugares propia de la escultura de lo que supuestamente podría pensarse que fuese lo esencial en ella -un hipotético debate y conquista del espacio- Heidegger queda confrontado a un problema crucial: el problema del volumen. Es llevado a sostener que aquello que en escultura se denomina con la palabra "volumen" tendría que perder dicho nombre pues su significado es tributario de la moderna ciencia técnica de la naturaleza. "¿Qué ocurrirá con el volumen de las formas escultóricas, formas que en cada caso encarnan un lugar? Probablemente ya no será un límite que separe entre sí las superficies de los espacios, alrededor de las que lo interno se trenza con lo externo"10.

Vemos que Heidegger se plantea, como consecuencia de su particular escucha de lo que habla en la lengua, dejar innominado algo que, desde siempre, ha sido definido como fundamento de la escultura, el volumen, y acerca del cual hemos visto que más allá de las modificaciones en la manera de concebir el hecho escultórico, es lo que permanece. Volumen positivo, cóncavo, abierto, perforado, reticulado, transparente, y en relación al espacio, volumen circunvalable, en relieve, flotante, pero siempre volumen. Se podría decir, en función de la aspiración de Heidegger a que el volumen de la forma escultórica ya no sea un límite que separe superficie de espacio, expresando la conveniencia de que lo que fue volumen cambie de nombre, que la operación ofrece para la escultura extremas dificultades.

${ }^{9}$ Heidegger, M. 1992, op.cit. (nota 8), p.57.

${ }^{10}$ Ibidem, p.59. 


\section{El lugar: anudamiento de materia, vacío y forma}

En el texto de presentación de la obra gráfica de Eduardo Chillida, Félix Duque habla de la copertenencia de forma y materia. Si la forma corresponde a "lo que puede ser" en función del saber hacer del artista, la materia por su lado pone el obstáculo de su dejar hacer, imponiendo qué es lo que con ella es posible hacer. Forma y materia se copertenecen en una lucha permanente, pues cada una hace presente lo que le falta a la otra: "Es más: cada una es la falta de la otra, y a la vez le hace falta para ser... en la obra cumplida, lograda"

Nos parece esencial esta noción de forma como límite, como frontera entre la materia y el espacio. Por lo que nos interesa sostener, vamos a contraponer materia y vacío, reservando la denominación de espacio ya sea para el espacio cotidiano -el espacio físico- tributario de la determinación matemática, o ya sea para otros espacios, de los cuales nos centraremos en particular en el espacio escultórico.

La forma opera en el acto escultórico como límite entre la materia y el vacío, jugando el juego "a la vez finito e interminable"12 entre el "poder-ser" y el "ser-posible". En ese juego se da la localización, la donación de lugares que en su inédita conexión producen la separación entre el espacio escultórico (en el cual acontece la obra lograda) y el espacio técnico-físico.

Puede así concebirse el acto escultórico como la generación de un espacio propio de la obra, un espacio resultante del triple anudamiento de materia, forma y vacío, con la concomitante donación de lugares.

La materia (tierra, madera, metal, piedra) impone las limitaciones de su propia condición, aquello que es posible hacer con esa materia determinada, lo que esa materia deja hacer con ella. La materia, a su vez, se halla inmersa o pertenece a un espacio físico del que hay que arrancarla. Pero ese arrancar la materia del espacio físico para trasladarla al espacio artístico no tiene nada que ver con ningún movimiento de traslado. Que el bloque de piedra sea trasladado al taller o se esculpa en la misma cantera es indiferente al traslado del que hablamos. Sólo la obra lograda traslada la materia, dándole otra localización con nuevas conexiones, lo cual no sólo funda un espacio sino que hace que destaque en tanto materia. El vaciamiento de la montaña propuesto por Chillida no trasladaría físicamente la montaña, pero al imponerle una forma determinada, si y sólo si en tanto obra fuese lograda, la habría trasladado al espacio artístico generado en ese acto.

${ }^{11}$ Duque, F., «Atalaya de encuentros» en catálogo de la exposición Eduardo Chillida. Obra gráfica, Museo de la Casa de la Moneda, 1995, p.15.

${ }^{12}$ Ibidem, p.17. 
¿Mediante qué procedimiento? proceder al vaciamiento de la montaña significa introducir el vacío en su interior: donde avanza el vacío retrocede la materia, donde la materia resiste se detiene el vacío. Entre ambos, la frontera constituida por la forma. A medida que el vacío penetra en el interior de la montaña, en pugna con esa particular materia rocosa, y según los caminos trazados por la forma, se van disponiendo lugares y se los va conectando. El saber hacer de Chillida habría estado en constante tensión con lo que la montaña, en tanto materia, hubiese dejado hacer al artista. . La estructura geológica es una gran masa de traquita, roca volcánica en la que predominan los silicatos: peculiar materia escultórica. Allí habría que practicar un hueco cúbico de unos 50 metros de lado (podría albergar a la iglesia de Santa Sofía en su interior). Tindaya es un cerro de 250 metros de altura, de laderas escarpadas y abruptas, circundado por una amplia llanura. Una montaña tradicionalmente mágica y considerada sagrada desde siempre, como atestiguan los petroglifos que se observan en la cima.

Vaciar la montaña es un procedimiento localizador. Vaciamiento que al proceder, localiza. Da lugar al mar, al sol, a la luna. Da lugar al día y la noche, a la luz y a las tinieblas. Movimiento y quietud, sonido y silencio, tiempo y espacio.

El constante movimiento del agua, la aparición y desaparición cíclica de los astros, el sonido del viento y el rumor del mar, los alternativos juegos de luces y sombras, todo eso y más en el recogimiento del silencio interior de la tierra.

Una escultura viva en la que la disposición de lugares y el modo de conectarlos nos imponga las escansiones y los cortes del tiempo. Una obra que coloque al hombre en la proximidad de cosas tan lejanas como el cielo y los astros, como el mar, que por estar siempre presentes parecen ser unos objetos más en la infinita red de objetos disponibles, modo propio de presentarse las cosas en nuestra era. Pero no por estar aparentemente al alcance de la mano, están próximas. La obra las aproximará al destacarlas en su lejanía. Se nos revelarán como lo más íntimo en su irreductible lejanía, surgiendo en nosotros los efectos de una apropiación expropiante.

¿Nos enseñará la montaña vacía a habitar la tierra? Al reunir en nosotros aquellos lugares, trasladándonos a otro espacio... ¿nos dejará aprender lo esencial del habitar? Un habitar la tierra que no es el simple respeto y admiración ante la naturaleza, sino el resultado de una intervención técnica sobre la misma (toda manifestación artística tiene una vertiente técnica, y muy especialmente el vaciamiento de una montaña), una intervención técnica que no se propone arrancarle sus frutos, abrirla y explotarla, emplazarla económicamente a un máximo rendimiento, sino que su finalidad sea la de conducir al hombre a su morada en la lengua, a esa relación en cierto modo imposible de las palabras y las cosas. Abrirnos a la extimidad. 


\section{La extimidad. El objeto, el vacío y la Cosa}

La extimidad no es lo contrario de la intimidad. La noción, extraída de la enseñanza de Lacan, ha sufrido en los últimos años un uso espúreo, como simple oposición de lo íntimo a lo éxtimo. Tal manera de utilizarla neutraliza su potencia, pues entiende la oposición de ambos términos como si de una esfera se tratase, en la cual su interior está netamente diferenciado del exterior. Pero toda la obra de Lacan es una lid contra la psicología de la esfera. El neologismo lacaniano ha surgido para indicar un lugar, el de una "exterioridad intima" cuya estructura remite a la complejidad que, en topología de superficies, corresponde al plano proyectivo y a la botella de Klein.

En la relación del sujeto con el Otro se genera un espacio, un lugar de exclusión interior, un "interior excluido" que fue denominado por Freud como "das Ding”, la Cosa, quedando situada "en el punto inicial, lógica y a la vez cronológicamente, de la organización del mundo en el psiquismo"13.

Alrededor de das Ding, de ese lugar de exclusión interior gira todo el movimiento de los significantes tanto inconscientes como preconscientes. Das Ding, la cosa, es de un orden radicalmente distinto a los significantes.

Das Ding no es un ente entre los entes, sino que es un lugar-exterioridad intima- esencial a la estructura. ¿Cuál es la diferencia fundamental con el objeto? Al quedar prohibido el acceso pulsional a la satisfacción en la relación incestuosa, el aparato psíquico queda condenado a una deriva en la que las pulsiones obtienen satisfacción significante: ahí viene la lista de objetos posibles que irán estableciendo puntos de fijación imaginaria para la satisfacción de la pulsión. Eso es el orden del objeto. Hecho notable en el retorno de lo reprimido, que se da por vía del significante. Es muy importante destacar que das Ding no es la ley del retorno, que en todo caso los rodeos y circunvoluciones del significante constituyen a das Ding como la causa. Leyes del inconsciente de combinación y sustitución de significantes puestas al servicio de producir a nivel del objeto una apropiación de lo excluído en el origen, la Cosa, que es así la causa.

Si en el retorno de lo reprimido de lo que se trata es de la vuelta de ciertos significantes que buscan satisfacciones sustitutorias en el síntoma, en la sublimación por el contrario no hay padecimiento. La satisfacción es de otro orden, pues sorteando la represión es alcanzada en un producto, en una obra. Y si Freud hablaba de un cambio de fin ( $\mathrm{Ziel}$ ) pulsional, consideramos que es en el pasaje del objeto tratado a la Cosa aproximada donde podemos concebir tal cambio de fin. No se trata del cambio de un objeto por otro, sino de una trans-

${ }^{13}$ Lacan, J., La ética del psicoanálisis. Seminario VII, Buenos Aires, Paidós, 1988, p.74. 
formación del objeto, produciéndose mediante dicho tratamiento una aproximación de la Cosa. La sublimación, para Lacan, es el acto por el cual un objeto resulta elevado a la dignidad de la Cosa.

La Cosa: lugar extranjero que Lacan no duda en situar como punto inicial -lógico y cronológico- de la organización del mundo. Cronología que lo llevará a calificar el lugar de la Cosa como "Otro prehistórico" ${ }^{14}$. Dimensión prehistórica del Otro que empujará a Lacan a una indagación en la prehistoria humana para recoger los primeros testimonios de la aproximación de la Cosa. Así, tomando apoyo en Heidegger, Lacan se dirigirá a la que para él quizás sea "la función artística más primitiva, la del alfarero"15.

También Heidegger, en el artículo Das Ding comentado por Lacan, es conducido a la Cosa a partir de consideraciones topológicas sobre la proximidad y la lejanía. "Próximo a nosotros está aquello que solemos llamar cosas", dice Heidegger, para asegurar a continuación que "Hasta ahora el hombre, de igual modo como no ha considerado lo que es la cercanía, tampoco ha considerado lo que es la cosa como cosa" ${ }^{16}$. Inicia una reflexión que desde el vacío esencial del vaso y lo lleno propio del escanciar, le permitirá arribar al Geviert -tierra, cielo, divinos, mortales- en que la cosa mundea, hace mundo. Geviert en que culmina la topología del ser como acaecimiento propicio.

Queremos decir que también para Heidegger la Cosa es esencialmente lugar. Y es en esa lectura donde Lacan interpreta que "lo vacío y lo pleno son introducidos por el vaso en un mundo que, por sí mismo, no conoce nada igual. A partir de este significante modelado que es el vaso, lo vacío y lo pleno entran como tales en el mundo, ni más ni menos y con el mismo sentido" ${ }^{17}$.

Desde esta perspectiva, el vaso puede ser considerado "como un objeto hecho para representar la existencia del vacío en el centro de lo real que se llama la Cosa" $"$.

Para la representación ese vacío es la nada, nihil, a partir de la cual el alfarero crea -ex nihilo- el vaso. "Hay identidad entre el modelamiento del significante y la introducción en lo real de una hiancia, de un agujero". Esta función agujereadora del significante será sostenida por Lacan hasta el final de su enseñanza. De allí que, en la época del seminario VII, la Cosa quede también definida como aquello de lo real primordial (lo real en su totalidad, tanto lo real del sujeto como lo real que le es exterior) que padece del significante.

\footnotetext{
${ }^{14}$ Ibidem, p.89.

${ }^{15}$ Ibidem, p.148.

${ }^{16}$ Heidegger, M., «La cosa», en Conferencias y artículos, Barcelona, Serbal, 1994, p. 144.

${ }^{17}$ Lacan1988, op.cit. (nota 13), p.149.

${ }^{18}$ Ibidem, p.151.
} 
Desde el acto de creación prehistórica realizado por el alfarero, Lacan pasa a desarrollar el momento supremo del paleolítico superior, el arte parietal, como emergencia del vacío en relación al significante.

Alrededor de esa exterioridad en el interior que es la Cosa, en el Seminario VII Lacan teje sus reflexiones en las que habla del enlace y la separación posterior entre arquitectura y pintura, así como de la progresiva conquista pictórica del espacio hasta llegar a pintar en el plano aquel vacío originario de la caverna, tal cual sucede en el objeto de la anamorfosis cuyo paradigma es en el análisis lacaniano el cuadro de Los embajadores de Holbein, en el que una mancha fusiforme se revela como una calavera al contemplarlo desde cierto ángulo.

"En el momento inicial, las imágenes que nos parecen ser las primeras producciones del arte primitivo fueron situadas en las paredes de una caverna"19. $\mathrm{El}$ artista elige por lo general una oquedad de muy difícil acceso, en la que las condiciones de iluminación y de ejecución de las pinturas debían de presentar grandes dificultades. Las pinturas paleolíticas guardan una estrecha relación "con ese algo que, en su subsistencia, se presenta con el carácter de un más allá de lo sagrado, que es justamente lo que intentamos fijar en su forma más general mediante el término de la Cosa".

¿Cómo entender ese "más allá de lo sagrado" denominado la Cosa? Consideramos que esta es la tesis fundamental de Lacan. Se le ha dado al arte rupestre un significado puramente artístico, o se lo ha supeditado en tanto arte a su supuesta función religiosa, e incluso se ha podido llegar a entenderlo, de acuerdo al conocimiento de anatomía animal y etología evidenciado por los artistas, como ciencia paleolítica. Pero arte, religión y ciencia no son para Lacan más que diversos tratamientos de la Cosa. Esa es la causa del arte paleolítico: la presentación de la Cosa. En torno a un vacío esencial el artista hace presente la Cosa dándole una pared simbólica. Unos milenios más tarde recogemos los ecos religiosos de este hecho en la erección del templo. Un autor como Francisco Jordá Cerdá interpreta en el campo de la arqueología a la pintura de la caverna como poniendo en juego de modo inaugural los dos elementos básicos de toda religión: el templo y la imagen ${ }^{20}$.

Lacan se desmarca de este tipo de interpretaciones al proponer la caverna y el templo como organizaciones en torno al vacío. Tal es la impresión en él suscitada por la catedral de San Marcos y aún más, el sentido final de toda arquitectura como organización significante alrededor de la extimidad del vacío.

\footnotetext{
${ }^{19}$ Ibidem, p. 172.

${ }^{20}$ Jordá Cerdá, F. Sentido y significación del arte rupestre peninsular, en Arte rupestre en España, Madrid, Zugarto Ediciones, 1987.
} 
A la luz de esta advertencia de Lacan, debemos evitar el dar cualquier significación mágica o sagrada a la "montaña vacía". Aunque parezca un templo (recordar que Santa Sofía cabría holgadamente en su interior) y aunque movilice toda la simbología sexual y generatriz que se quiera (sol/luna, agua/tierra, etc.,) la montaña vacía de Tindaya, más allá de lo sagrado, será un lugar, un lugar de presentación de la Cosa. El hombre, convocado a ese recinto en el interior de la montaña, en el recogimiento más íntimo, se abismará en lo inconmensurable.

Concebimos la Cosa como un lugar generador de espacios. Es un vacío localizador, un vacío que da lugar, que funda y conecta lugares otorgando espacios.

\section{La montaña vacía}

El proyecto de la montaña vacía anuncia una espectacular intervención sobre el medio natural. Actualmente, y muy especialmente en Estados Unidos, son frecuentes las manipulaciones escultóricas de la naturaleza que conducen a profundas modificaciones del paisaje. Diversos earthworks ponen de manifiesto las más aventuradas creaciones del land art. Como sostiene Javier Maderuelo en el capítulo de su libro dedicado a este tema, padecemos "un distanciado olvido de aquellos parajes en que los hombres, como topos, hoy todavía, siguen entrando en las entrañas de la tierra para recoger las rocas que hacen fuego, se endurecen, brillan o espejean, esas piedras que son capaces de matar o trastornar hasta hacer perder la razón. En estos parajes el hombre ha ido escribiendo como lo hace con la arquitectura en la construcción y crecimiento de la ciudad, toda su historia. Son lugares, como explica la escultora hispano-austríaca Eva Lootz, cargados de lenguaje"21.

Todos aquellos espacios que han sido removidos y estimulados por el hombre, como son las minas y las canteras, son definidos por esta escultora como espacios excitados. La tentación por excitar el espacio ya aguijoneaba al hombre primitivo. Sus asentamientos al lado de minas, ríos o canteras así lo prueba. La ciudad de Siracusa, en Sicilia, surgió:

al pie de una cantera, y el propio hueco de la cantera se convertía en un espacio destinado al arte al asentarse naturalmente en él uno de los más soberbios anfiteatros. Aún hoy, pasados más de veinte siglos, cantera y

\footnotetext{
${ }^{21}$ Maderuelo, J., El espacio raptado, Madrid, Mondadori, 1990, p. 180.
} 
anfiteatro se siguen utilizando. Los artistas del land art lanzan la idea de reinterpretar las canteras como una gran escultura que, con el lento paso del tiempo, va cambiando de contornos...22

La cuestión de la relación entre la utilidad de la cantera y la función de la obra de arte es parte esencial del proyecto Chillida: "Los obreros de una cantera sacan la piedra pero meten el espacio". Esta reflexión sobre el trabajo, unida a la realización de alguna escultura en alabastro en que prefiguraba la montaña vacía, fueron preparando el terreno del actual proyecto. Chillida llega a sintetizar la intersección necesaria entre obra y cantera en los siguientes términos: "para mí el espacio, para los otros la piedra"23. Vemos que la relación canteraescultura es distinta a lo que hemos comentado de los planteamientos del land art. Es otra manera de considerar el límite entre espacio y materia. La noción de trabajo del cantero resulta esencial tanto a la intuición de la montaña vacía como a las ideas de los artistas del land art. Al extraer los bloques y dejar los correspondientes huecos, hace posible que la visión del escultor se fije en uno u otro lado de la frontera: acentúa el espacio o resalta la materia, pero siempre ambos en tensión, sugeridos y solicitados recíprocamente el uno por la otra.

De la importante muestra de artistas del land art, retengamos algunos nombres y obras en las que se intenta conectar lugares de una manera novedosa, generando un nuevo concepto de espacio, obras que por ello entran en resonancia con el proyecto de la montaña vacía.

De especial interés es una obra de Nancy Holt titulada Sun Tunnels. Fue construida en 1976 en un desierto de Utah, siguiendo la tradición de varios escultores de instalar sus obras en los inmensos desiertos estadounidenses. La obra que comentamos está constituida por cuatro grandes tubos cilíndricos de casi tres metros de diámetro por el doble de largo. El espectador puede circular por el interior de estos tubos que están acostados sobre el terreno y dispuestos en cruz, separados unos de otros por una distancia de quince metros.

Los cilindros están alineados con la salida y la puesta del sol, en los solsticios de verano e invierno, de tal manera que durante la salida y la puesta del sol, los días de los solsticios y durante diez días antes y después, el sol es visible a través de los conductos. La relación entre interior y exterior se establece a través de unas perforaciones realizadas en los tubos, a modo de pequeños orificios circulares dispuestos sobre la superficie de

\footnotetext{
${ }^{22}$ Ibidem, p. 182

${ }^{23}$ Samaniego 1995, op.cit. (nota 7).
} 
los túneles según el diseño de las constelaciones de Drago, Perseo, Columba y Capricornio, tal como se representan en los mapas celestes, de tal forma que estas aberturas varían en su diámetro entre veinte y treinta centímetros, según el tamaño relativo de la estrella a la que representan. Durante el día la luz del sol, y por la noche la de la luna, penetra por los agujeros proyectando sus haces de luz sobre la cara interior de los tubos. Estas manchas luminosas, como en un planetario, se van desplazando lentamente, según el sol o la luna se mueven en el firmamento. ${ }^{24}$

En un proyecto de los años setenta, otro artista, James Turrell, buscó durante mucho tiempo alguna colina o volcán que permitiese situar al espectador en el centro de una planicie inmensa, la del desierto circundante, pero elevado respecto de ella: "un lugar que tuviese las cualidades perceptivas de un espacio infinito". En un volcán extinguido en Arizona proyectó diversos sitios en los cuales se pudiesen experimentar las cualidades del sol y de la luna. Un largo túnel conduciría a los lugares desde los cuales el espectador podría observar acontecimientos tales como la salida de la luna o la puesta del sol. "La gran ambición de Turrell es revelarnos las extraordinarias propiedades físicas y simbólicas de la luz, uno de los lugares comunes de nuestras vidas, intentando crear un ambiente de éxtasis" 25 .

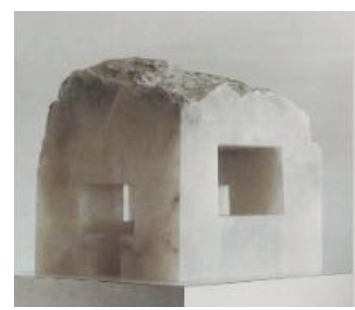

Chillida, E. «Montaña Vacía» (Alabastro, 1984)

http://librivision.artium.org/dossieres/AR00090/proyectotindaya.htm

En estos y otros proyectos y obras insisten los elementos que juegan en el proyecto de Chillida: el sol y la luna. Incluso podemos afirmar que en ellos está mucho más calculada la incorporación del tiempo y del movimiento. Sol y luna surgen a ciertas horas, en ciertas épocas. Su luz se mueve a través de una serie de agujeros filtrantes para reflejarse sobre paredes curvas.

De ello se deduce que llevar la luz del sol y de la luna al interior de la montaña requeriría complejas formas de las perforaciones y tal vez su multiplica-

\footnotetext{
${ }^{24}$ Maderuelo 1990, op. cit. (nota 21), p.189.

${ }^{25}$ Ibidem, p. 192.
} 
ción: un túnel para la luna y otro para el sol, tal cual se esbozaba en la primera maqueta, son simplemente la síntesis de las dimensiones que se ponen en juego, una manera simple de nombrarlas. El mar -la mar, como él lo llama-es el tercer elemento que introduce un movimiento mucho más cambiante e imprevisible. La mar suena, es el sonido y la furia. "La mar" es la marca de Chillida: “...estoy conectado con la mar como un discípulo con su maestro. La mar está siempre viniendo, viniendo con una fuerte insistencia, luchando. Siempre nunca es diferente pero nunca siempre igual. ¿Por qué la mar está siempre viniendo?"'26.

"Montaña vacía" fue para Chillida el nombre de un sueño realizado en alabastro [Mendi Hutz, 1984]. Al despertar tiempo después surgió la idea de horadar la montaña. Errática, merodeó geografías hasta localizarse en Tindaya. Ocurrencia, revelación, epifanía, la idea no es la obra, ni siquiera es un a priori que dice lo que será la obra.

Una obra es una idea artística en el momento en que se termina, no en el momento en el que se empieza o en el que se te ocurre la idea, lo que llamamos idea. Las ideas en el arte se concretan y se manifiestan cuando las obras están terminadas. Y además, curiosamente, las obras cuando se terminan están muertas para el que las ha hecho. Se te han muerto. Han vivido contigo todo un proceso y se han muerto un día. Al morirse un día es cuando empiezan a servir para los demás, es cuando la obra nace para los demás, pero para ti deja de tener un interés directo, puesto que ya está concluida. Eso es para mí el proceso verdadero y creo que es así en todas las artes. ${ }^{27}$

La montaña vacía fue una idea de Chillida, fue para él un despertar que no plasmó en obra, que se fue estrellando contra múltiples obstáculos erigidos por las políticas de las fuerzas que operan en los espacios públicos, munidas de argumentos sociológicos, ecológicos, económicos, arqueológicos, religiosos, etnológicos... En esos meandros se fue enlenteciendo la corriente, entreteniéndose en el rizoma cenagoso de los papeles y despachos, hasta que, agotada, exhausta, desprovista de su vigoroso impulso, la idea inaugural se fue adormeciendo. Después, la enfermedad y la muerte.

Hoy, la idea que despertó a Chillida no es más que, para los afortunados, el resto diurno de un sueño. Para la mayoría, en cambio, ha caído en el olvido del

\footnotetext{
${ }^{26}$ Boulting 1985, op. cit. (nota 6).

${ }^{27}$ Chillida 2005, op.cit. (nota 2) p. 94.
} 
profundo sopor de un dormir sin siquiera fenómenos oníricos. Lo que se ha perdido para siempre es la idea artística cuya manifestación sólo el hacer de Chillida en Tindaya hubiese hecho posible.

Esa idea que lo despertó una noche, es para mí un sueño. Recorro una y otra vez las entrañas de Tindaya. Veo estrellas, nubes, horizonte. Suenan el viento, la lluvia, el mar incesante. Lentos desplazamientos del sol y la luna, juegos de luces y sombras que producen sus rayos dentro de la inmensa cavidad. Y en todo aquello habla Chillida: "las obras son ecos que conservan en el tiempo, para el oído hermano, la voz sorda de la luz" ${ }^{28}$.

Voz sorda de la luz, sonora voz del mar, venid al corazón de la montaña a oficiar la extimidad. Cálida luz del sol y luz fría de la luna, anudándose con el mar, pura agitación y sonido. Al fin, apropiándome de lo más lejano, me expropio en la inmediatez de mi abismo. Sólo así, sin dios, sin rey, sin padre habitaré la tierra.

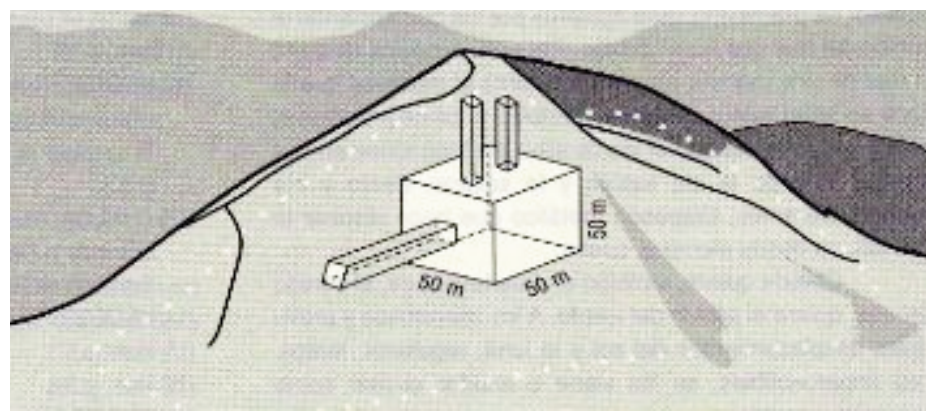

Samaniego, F. « Chillida penetra en una montaña sagrada», El País, 30 de julio de 1995.

${ }^{28}$ Ibidem, p. 41. 